\title{
Markov Regime-Switching Autoregressive Model of Stock Market Returns in Nigeria
}

\author{
Oluwasegun A. Adejumo, ${ }^{1}$ Seno Albert ${ }^{1}$, and Omorogbe J. Asemota ${ }^{2}$
}

This study is designed to model and forecast Nigeria's stock market using the All Share Index (ASI) as a proxy. By employing the Markov regime-switching autoregressive (MS-AR) model with data from April 2005 to September 2019, the study analyzes the stock market volatility in three distinct regimes (accumulation or distribution - regime 1; big-move - regime 2; and excess or panic phases - regime 3) of the bull and bear periods. Six MS-AR candidate models are estimated and based on the minimum AIC value, MS(3)-AR(2) is returned as the optimal model among the six candidate models. The MS(3)-AR(2) analysis provides evidence of regime-switching behaviour in the stock market. The study also shows that only extreme events can switch the ASI returns from regime 1 to regime 2 and to regime 3, or vice versa. It further specifies an average duration period of 9, 3 and 4 weeks for the accumulation/distribution, big-move and excess/panic regimes respectively which is an evidence of favorable market for investors to trade. Based on Root Mean Square Error and Mean Absolute Error, the fitted MS-AR model is adjudged the most appropriate ASI returns forecasting model. The study recommends investments in stock across the regimes that are switching between accumulation/distribution and big-move phases for promising returns.

Keywords: All share index, Markov process, regime switching, stock market, volatility

JEL Classification: C13, C22, C52, C58

DOI: $10.33429 /$ Cjas. $11220.3 / 8$

\section{Introduction}

The modelling of volatility and the forecast of financial markets has attracted the attention of investment analysts, exchange and security analysts and risk managers (Poon \& Granger, 2003). While modelling the stock market volatility, most financial analysts are specifically interested in obtaining worthy estimates of the conditional variance (a distinctive feature of volatility) in order to enhance portfolio shares or its risk management. Over the years, a series of models have been established to evaluate the conditional volatility of stock markets. The Engle (1982) generalized autoregressive conditional heteroscedastic (GARCH) models are

\footnotetext{
${ }^{1}$ Department of Statistics, University of Abuja. Corresponding Author: olushegzy006@ gmail.com

${ }^{2}$ Research Department, National Institute for Legislative and Democratic Studies, Abuja.
} 
the commonly used models for volatility forecast in stock markets. Thus, accurate measure and forecast of volatility are applied to asset-pricing models as a simple risk measure as well as derivative pricing theories and trading (Andersen \& Bollerslev, 1998; Barndorff-Nielsen \& Shephard, 2002). It must be pointed out that prior to the introduction of conditional volatility models, there were the Box-Jenkins (1976) models, specifically, the Autoregressive Integrated Moving Average (ARIMA) models. However, ARIMA models are based on the inaccurate assumptions of constant variance for the time series of stock market returns (Goldfeld \& Quandt, 1976; Hamilton, 1989; Shamsuddeen et al., 2015). This shortcoming of ARIMA models has led to the emergence of various types of Engle-like models (examples are Tule, Dogo \& Uzonwanne, 2018; Maqsood et al. 2017; Yaya, Akinlana \& Shittu, 2016; Bala \& Asemota 2013; Wang, 2006; Longmore-Robinson, 2004; Brooks \& Burke, 1998; Tse \& Tsui 1997; McKenzie, 1997; Jorion, 1995; Pesaran-Robinson, 1993; Lastrapes, 1989; Hsieh, 1989; Taylor, 1987; Milhoj, 1987; Meese \& Rogoff, 1983). These new methods adopted various extensions of the GARCH models like the GARCH-M, IGARCH, EGARCH, TGARCH and PARCH which take into consideration the possibility of variations in the stock market.

A further example of stock market volatility models is the regime-switching model, which was developed by Hamilton (1989). This model has become very prevalent in applied research. Regime-switching model has gained the attention of many scholars like Calvet and Fisher (2004), Masoud, Hamidreza and Safael (2012), Beckmann and Czudaj (2013), Lux, Morales-Arias and Sattarho (2014), Nguyen and Walid (2014), Aliyu and Wambai (2018). They have documented the distinctiveness and forecasting capabilities of Markov regimeswitching against the commonly used GARCH models. Additionally, the Markov regimeswitching method of volatility analysis has recorded some advantages over time.

According to Dow theory, it is recognized that the bull and bear markets of stock market returns are primarily and distinctly characterized by three regimes or phases: the bull market has the accumulation, big-move (public participation) and excess regimes while the bear market has the distribution, big-move and panic (despair) regimes (Adam, 2020), Markov regime-switching method has proven to be more reliable in this aspect in that it models all observed structures of the stock market returns. The observed eras characterized in the series such as bull and bear markets as well as interventions can be modeled in different regimes of the Markov regime-switching model. An innovative feature of the Markov regime-switching 
is that the mechanism of switching is determined by an unobservable regime variable which follows first order Markov-Chain (Hamilton, 1989). Interestingly, while the application of the Markov regime-switching method has increased in other parts of the world and despite the attractiveness and unique features of the model in analyzing financial market volatility, yet to the best of our knowledge, no evidence of Markov three regimes-switching model have been used to model the three distinct phases of Nigeria's stock market eras (bull or bear). Close studies are Aliyu and Wambai (2018), and Yahaya and Adeoye (2020). Both studies examined the volatility of Nigeria's stock market using Markov two regime-switching to model the bull and bear markets. However, both studies did not consider the three distinct phases (the accumulation or distribution, big-move and excess or panic regimes) of the stock market eras (bull and bear) as identified by Dow theory and the investors. As described by Adam (2020), the three distinct phases serve as indicators for investors to guide in allocation of stocks, also to know when to invest and sell. Hence, it is against this background that this study seeks to analyze Nigeria's stock market volatility in three distinct phases namely: the accumulation or distribution, big-move and excess or panic regimes.

This study models Nigeria's stock market returns using the Markov three-regime switching model. Specifically, the study analyzes the Nigeria stock market volatility in the accumulation or distribution, big-move and excess or panic regimes; estimates the transition probabilities of each of the regimes; estimates the expected durations of each of the regimes; and to forecast Nigeria's stock market volatility.

The rest of this paper is ordered as follows. Section 2 provides a brief description of theoretical and empirical literatures, Section 3 presents the research methodologies. Data analysis and results are discussed in Section 4. Section 5 provides conclusion and policy recommendations.

\section{Literature Review}

\subsection{Theoretical Literature}

The application of regime switching models has ranged over wide areas of research, such as modeling the swings in exchange rate, inflation rate, interest rate, stock prices, and the changes in government policy. The modeling of swings, known as regime switching in the financial market, started far back in 1958 when Quandt introduced the switching regression model (Aliyu \& Wambai, 2018). Subsequently, Goldfeld and Quandt (1976) extended the 
switching regression model to tolerate the shifting of regimes to follow Markov process. Afterwards, Hamilton (1989 and 1990) built on Goldfeld and Quandt (1976) studies. Hamilton examined the shifts of regimes in dependent observations and developed the branded Markov regime-switching model. The Markov regime-switching model was developed to arrest swift shifts in time-series with the assumption that regime is an unobservable stochastic process, that is movement within regimes are distinct. Additionally, more than accommodating the regimes, frequently, the identified regimes, using econometric procedure are intrinsically linked to different eras in policy, regulation and other variations. Also, the Markov regime-switching model estimates the transition probabilities and the expected duration of the regimes.

\subsection{Empirical Literature}

Masoud et al. (2012) assessed the dynamic behaviors of Iran's exchange rate using the Markov regime-switching model and other five different modeling approaches. The six models were compared based on their performances (using their AIC and BIC values) in capturing the dynamic behavior of exchange rate, their results identified the Markov regime-switching model as the best fit model among the six modeling approaches to evaluate the dynamic behavior of Iran's exchange rate. They observed a dramatic jump in the early part of 2002 which coincided with the change in exchange rate regime. Also, Beckmann and Czudaj (2013) examined the inter-relationship between oil prices and dollar exchange rates such as the nonlinear adjustment dynamics, using a Markov-switching vector error correction model. Their results showed that the error-correction of the series short-run follows Markov regimeswitching, entrenched within a long-run linear cointegrating relationship. In the same way, Zhu-Zhu (2013) examined the surplus returns of the US stock market. They modeled the stock market returns using 15 financial variables as predictors of the surplus returns. They utilized the regime-switching combination process to model uncertainty in 3-dimensions. Their finding depicted 2-regimes that were connected to the US business cycle. The depreciation regime was connected to economic growth while the appreciation regime was related to economic decline, which implies that surplus returns are more predictable during economic recession and less predictable when the economy booms.

Moreover, Nguyen and Walid (2014) investigated the dynamic relationships between stock market and exchange rate returns of Brazil, China, India, Russia and South-Africa. They 
utilized the Markov regime-switching model. Their findings revealed that the stock market returns of these countries evolved based on low variance and high variance regimes. Also, the Markov regime-switching models provide evidence that stock markets in these countries have an effect on exchange rates during both bear and bull eras. Lux et al. (2015) applied the markov-switching multifractal model and the GARCH-type models to estimate oil price volatility. Based on the superior predictive ability (SPA) test and six loss functions, their forecasting performance were evaluated and compared at short and long horizons. The empirical results revealed that the new Markov-switching multifractal model came out as the model that cannot be outperformed by other models across the forecasting horizons and subsamples. Aikaterini (2016) investigated the forecast power of Markov regime-switching models for the returns of Canadian, UK and US daily stock markets. Aikaterini's findings revealed that the regime's transition probabilities were very small, which implies the probability of regime changes is low. Hence, Aikaterini's model is a single regime model since the transition probabilities are very low. The expected duration of regimes staying in the appreciation era is high compared to the depreciation era, however the impacts were significantly strong in the depreciation era.

Recently, Aliyu and Wambai (2018) examined the spillover volatility between the Nigeria's stock market and exchange rate using the Markov regime-switching model. Their approach tolerated regime-shift in the series' mean and variance. The results revealed that the exchange rate and stock market returns were not normally distributed and had ARCH effects and unit root. Also, the evidence from two-regimes estimation established higher transition probabilities in the depreciation era compared to the appreciation era. Afterwards, they studied the spillover volatility between the stock market and exchange rate. Moreover, Korkpoe and Howard (2019) examined the volatility model for Botswana, Ghana, Kenya and Nigeria equity markets using the Markov regime-switching Bayesian method. They adopted Markov two regime-switching models to select the best models that describe the markets' returns, they found heterogeneity in the evolution of volatility across the equity markets and the Markov two regime-switching described better the heteroscedastic returns generating processes. Also, Yahaya and Adeoye (2020) examined the Nigeria's stock market volatility by comparing different lags of Markov two regime-switching models. They found that over the years, investors had been exposed to certain risks and the financial crisis among others was the major cause of stock market volatility. However, while the literature on Markov 
regime-switching has increased recently, there are still limited studies that examine the three regimes, that is, the accumulation or distribution, big-move and excess or panic regimes, of the Nigeria's stock market. It is on this background that this research is being carried-out.

\section{Data and Methodology}

\subsection{Data}

The weekly data of Nigeria All Share Index (ASI) was utilized in this study. The data were sourced from Nigeria Stock Exchange website and cover the period of April 2005 to September 2019.

\subsection{Model Specification}

In modeling the Markov Switching Autoregressive (MS-AR) process, we specifically consider a three regime-switching with state-dependent mean and state-dependent variance for $r_{t}=\log \left(\frac{y_{t}}{y_{t-1}}\right)$ [i.e. $r_{t}$ is the ASI-Returns (ASIR); where $y_{t}$ is the value of ASI at time $\left.t\right]$ as follows:

$$
\begin{aligned}
& r_{t}=c_{s_{t}}+\Phi_{1}\left(r_{t-1}-c_{s_{t}-1}\right)+\Phi_{2}\left(r_{t-2}-c_{s_{t}-2}\right)+\Phi_{3}\left(r_{t-3}-c_{s_{t}-3}\right)+e_{t}, \\
& e_{t} \sim \text { i.i.d } N\left(0, \sigma_{S t}^{2}\right)
\end{aligned}
$$

where:

$$
c_{s_{t}}=c_{0} S_{0 t}+c_{1} S_{1 t}+c_{2} S_{2 t}+c_{3} S_{3 t} ; \quad \sigma_{S_{t}}^{2}=\sigma_{1}^{2} S_{1 t}+\sigma_{2}^{2} S_{2 t}+\sigma_{3}^{2} S_{3 t}
$$

$c_{s_{t}}$ is the state dependent mean, $\sigma_{S_{t}}^{2}$ is state dependent variance and the autoregressive coefficients are $\Phi_{1}, \Phi_{2}$ or $\Phi_{3}$; which could be different for different subsamples. The proposal will be to model the regime $S_{t}$ as the outcome of an unobserved 3-state Markov chain with $S_{t}$ independent of $e_{t}$ for all t.

The MS-AR model of three regimes, is a model that switches regimes stochastically, it was initiated by Hamilton (1989). Alternatively, Mendy and Widodo (2018) stated a MS-AR model of three regimes with an AR process of order $p$ as follows;

$$
r_{t}= \begin{cases}a_{1}+\beta_{11} r_{t-1}+\cdots+\beta_{p 1} r_{t-p}+\varepsilon_{t} & S_{t}=1 \\ a_{2}+\beta_{12} r_{t-1}+\cdots+\beta_{p 2} r_{t-p}+\varepsilon_{t} & S_{t}=2 \\ a_{3}+\beta_{13} r_{t-1}+\cdots+\beta_{p 3} r_{t-p}+\varepsilon_{t} & S_{t}=3\end{cases}
$$

where the regimes are indexed by $S_{t}$. In MS-AR model, the intercept and the parameters of the AR part are reliant on $S_{t}$ at time $t$. The $S_{t}$ is presumed to be distinct unobservable variables. Hence, this paper labels $S_{1}$ (regime 1) as accumulation or distribution phase of the All 
Share Returns $\left(r_{t}\right), S_{2}$ (regime 2) symbolizes big-moves phase of the All Share Returns $\left(r_{t}\right)$ and $S_{3}$ (regime 3) symbolizes excess or panic phase of All Share Returns $\left(r_{t}\right)$. The transitions of the $S_{t}$ (regimes), are presumed to be ergodic and intricate $1^{\text {st }}$ order Markov-process. This means impacts of earlier observation(s) for the $r_{t}$ and regime(s) is/are completely captured in the recent $r_{t}$ regime(s) observations as represented in (4);

$$
\rho_{i j}=\operatorname{Prob}\left(S_{t}=\frac{j}{S_{t-1}}=i\right) \quad \forall i, j=1,2,3 \quad \sum_{i=1}^{3} \rho_{i j}=1
$$

Matrix $\mathrm{P}$ captures the probability of switching which is known as a transition matrix;

$$
P=\left[P_{11} P_{12} P_{13}, P_{21} P_{22} P_{23}, P_{31} P_{32} P_{33}\right]
$$

where $P_{11}+P_{12}+P_{13}=1, P_{21}+P_{22}+P_{23}=1$ and $P_{31}+P_{32}+P_{33}=1$. The nearer the probability $\rho_{i j}$ is to one the longer it takes to shift to the next regime.

The diagonal element of the matrix of the transition probabilities in (5) contain important information on the expected duration on the state of the regime. Let $D$ be defined as the duration of state $j$; we have:

$$
\begin{aligned}
& D=1, \text { if } S_{t}=j \text { and } S_{t+1} \neq j ; \operatorname{Pr}[D=1]=\left(1-p_{j j}\right) \\
& D=2, \text { if } S_{t}=S_{t+1}=j \text { and } S_{t+2} \neq j ; \operatorname{Pr}[D=2]=p_{j j}\left(1-p_{j j}\right) \\
& D=3 \text { if } S_{t}=S_{t+2}=S_{t+3}=j ; \operatorname{Pr}[D=3]=p_{j j}^{2}\left(1-p_{j j}\right) \ldots
\end{aligned}
$$

Then, the expected duration of regime $j$ can be derived as:

$$
\begin{aligned}
& E(D)=\sum_{j=1}^{\infty} j \operatorname{Pr}[D=j] \\
& \begin{aligned}
\sum_{j=1}^{\infty} j \operatorname{Pr}[D=j] & =\operatorname{Pr}\left[S_{t+1} \neq j \mid S_{t}=j\right]+2 \times \operatorname{Pr}\left[S_{t+1}=j, S_{t+2} \neq j \mid S_{t}=j\right] \\
& +3 \times \operatorname{Pr}\left[S_{t+1}=j, S_{t+2}=j, S_{t+3} \neq j \mid S_{t}=j\right]+\ldots \\
= & \left(1-p_{i j}\right)+2 \times p_{j j}\left(1-p_{i j}\right)+3 \times p_{j j}^{2}\left(1-p_{i j}\right)+\ldots=\frac{1}{1-p_{i j}}
\end{aligned}
\end{aligned}
$$

Hence the expected duration for the system to stay in each regime is calculated as;

Expected duration $=\frac{1}{1-P_{i j}}$.

\subsection{Estimation Procedure}

Prior to Markov Switching Autoregressive (MS-AR) modelling we determine whether the Nigeria All-Share returns $\left(r_{t}\right)$ is suitable for the nonlinear model (MS-AR). Nonlinear models are employed where the financial system suggests nonlinearity in the system (Mendy \& 
Widodo, 2018). We utilized the most widely used tests known as BDS test by Brock, Dechert and Scheinkman (1987). The BDS statistic is defined as follows;

$$
B D S_{q \cdot Q}(r)=\sqrt{Q} \frac{C_{m}(r)-C_{1}{ }^{r}(r)}{\sigma_{q \cdot Q}(r)}
$$

The $Q$ in (8) is the bounded points of the area with q dimension, $r$ represents radius of the sphere centered on $X_{i}, C$ denotes constant while $\sigma_{q . Q}$ denotes standard deviation of $\sqrt{Q} C_{m}(r)-C_{1}{ }^{r}(r)$. Hence, the null hypothesis to be tested in the BDS test is that the series are linearly dependent.

In modelling volatility, the choice of an appropriate model from variant classes of models portrayed in the underlying data is often a difficult task. The importance of choosing the best model in time series analysis cannot be over emphasized. Model selection principles is a suitable tool in this respect to assess if the fitted model suggests optimum balancing between parsimony and goodness of fit. This study utilized the frequently used model selection principle - Akaike Information Criterion (AIC).

$$
A I C=T \ln (\text { residual sum of squares })+2 n,
$$

where $T$ is the numeral of operational observations, while $n$ is the number of parameters to be evaluated. The log-likelihood of the fitted model was also utilized. Hence, the best model is one with the smallest AIC value and highest log-likelihood.

Frequent error measures are available for forecasts evaluation after estimation. We therefore evaluate the forecasting ability of the MS-AR model by means of four different loss functions. These are Root Mean Squared Error (RMSE), Mean Absolute Error (MAE), Mean Absolute Percentage Error (MAPE) and Theil's U statistic. The Theil's U statistic compares the forecast accuracy of different models. It has the plus to provide an immediate comparison of the forecasts with those of the simple methods.

\section{Results and Discussion}

Summary statistics of the ASI $\left(y_{t}\right)$ and its returns (ASIR; $r_{t}=\log \left(\frac{y_{t}}{y_{t-1}}\right)$ ) are shown in Table 1. As observed from Table 1, ASI has mean, median, maximum and minimum of 32046.49, 29391.21, 66162.17 and 19862.69 respectively for the time period examined. ASI has standard deviation and Jarque-Bera statistic values of 9828.28 and 227.59 respectively. Similarly, the ASI returns (ASIR) has a mean of 0.00012, minimum of -0.0546 and maximum of 0.0507 . 
Considering the probability value of the variable, it can be deduced that the p-value $(0.00<$ 0.01 ) suggests non-normality for both ASI and ASIR at 1\% level of significance. Figures 1 and 2 present the time series plot of ASI and ASIR $\left(r_{t}\right)$ series.

Table 1: Summary Statistics

\begin{tabular}{lll}
\hline & ASI & ASIR $\left(r_{t}\right)$ \\
\hline Mean & 32046.49 & 0.00012 \\
Median & 29391.21 & -0.0002 \\
Maximum & 66162.17 & 0.0507 \\
Minimum & 19862.69 & -0.0546 \\
Std. Dev. & 9828.28 & 0.0119 \\
Jarque-Bera & 227.59 & 334.6028 \\
Probability & 0.00 & 0.00 \\
Observations & 753 & 752 \\
\hline
\end{tabular}

Source: Researchers' computations

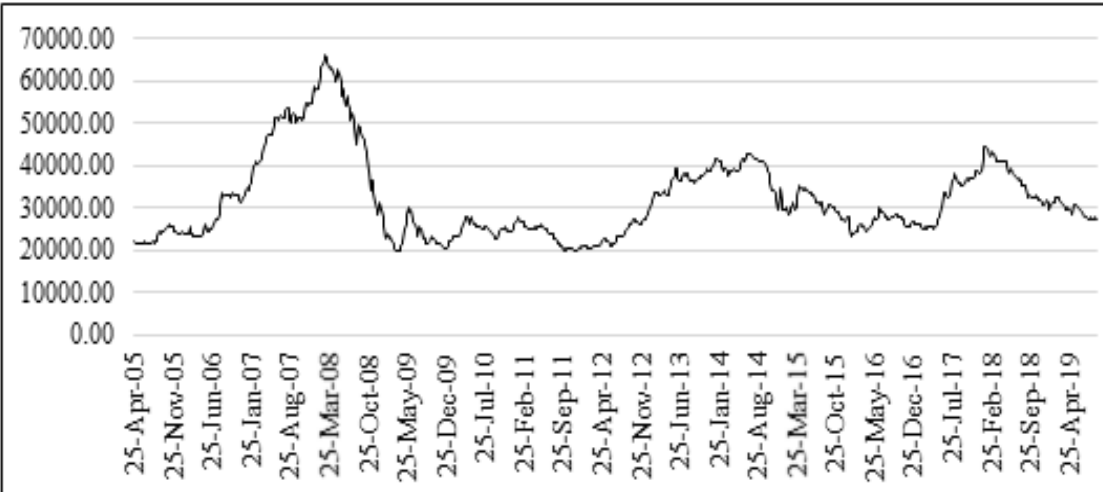

Figure 1: ASI Time Series Plot

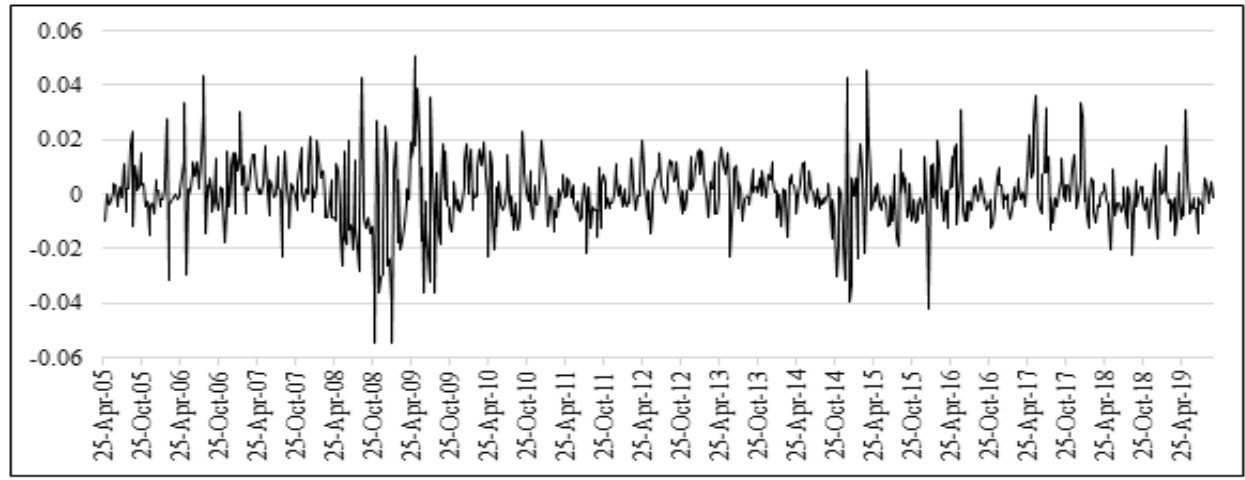

Figure 2: ASIR $\left(r_{t}\right)$ Time Series Plot 
As observed from Figure 1, March 2008 Nigeria recorded the peak (65622.67) ASI. As a matter of fact, the ASI boomed between 2006 to 2008, this was due to the consequence of rise in oil price, market discipline, consumer sophistication and banking system flooded by oil revenue (Adeolu, 2012). The ASI dropped abruptly in 2009 and was relatively constant between April 2009 to November 2012. This was as a result of the global financial crisis, Nigeria banking crisis (30 billion-naira market cap erased in one day; banking index down to $34.69 \%$ ) and unfavorable interest rates (Adeolu, 2012). ASI rose steadily between December 2012 to October 2014 as a result of rise in oil revenue, it dropped in February 2015 and was relatively constant till May 2017. This can be ascribed to the effect of economic recession in Nigeria. ASI also rose steadily as the country was coming out of recession between July 2017 to April 2018. To end, ASI declined progressively from June 2018 till September 2019. Additionally, the returns plot (Figure 2) empirically shows clustering volatility in the series which depicts that small and large returns result in clusters i.e. returns that are large are thrived by larger returns also small returns are thrived by smaller returns. This implies that eras of high ASI are often succeeded by eras of high ASIR, and low ASIR are prospective to be succeeded by lower ASIR. Hence, the evidence of clustering volatility in Figure 2 suggests that ASIR are conditionally heteroscedastic and can only be estimated by volatility models such as MS-AR model.

\subsection{Result of ARCH test}

Before MS-AR estimation, ASIR was tested for Heteroscedasticity. The results are presented in Table 2. The results provide evidence (i.e. p-value $<0.01$ ) to reject $H_{0}$ (null hypothesis) in favor of $H_{1}$ (alternative hypothesis). Hence, ASIR exhibits ARCH effect. Therefore, it is suitable to apply MS-AR models that will sufficiently handle the changing variance in ASIR since the return series meets the pre-conditions for the MS-AR models.

Table 2: ARCH Test

\begin{tabular}{llll}
\hline Variable & $x^{2}$ & D.F & P-value \\
\hline ASIR & 174.0707 & 52 & $0.000^{*}$ \\
\hline
\end{tabular}

Note: $H_{0}$ : there is no ARCH effects vs. $H_{1}$ : there is ARCH (p) disturbance.* denotes significant at $1 \%$ level.

Source: Researchers' compilation EViews Output 


\subsection{Nonlinearity Test: The Brock, Dechert, and Scheinkman (BDS) Test.}

The ASIR data was tested for nonlinearity. Table 3 presents the results of the nonlinearity test. The BDS results show that the probabilities are less than $1 \%$ level of significance, consequently imply a rejection of the null hypothesis of linearly dependent. This result is a signal of messy behaviour of financial time series, therefore ASIR is modeled using a nonlinear model (MS-AR model).

Table 3: Nonlinearity Test (BDS)

\begin{tabular}{lllr}
\hline Dimension & Test & BDS Z- & Prob. \\
& Statistic & Statistic & \\
\hline Two & 0.0398 & 10.9586 & $0.000^{*}$ \\
Three & 0.0691 & 11.9667 & $0.000^{*}$ \\
Four & 0.0869 & 12.6350 & $0.000^{*}$ \\
Five & 0.0932 & 13.0029 & $0.000^{*}$ \\
Six & 0.0919 & 13.2811 & $0.000^{*}$ \\
\hline \multicolumn{4}{l}{ Note: * denotes significant at 1\% level of signifi- } \\
cance.
\end{tabular}

\subsection{Estimation of Markov Switching Autoregressive Model [MS-AR]}

Table 4 presents the summary of the estimates of six MS-AR candidate models for ASIR series. Using the specification measures that is log-likelihood and Akaike information criterion (AIC), among the six estimated MS-AR models MS(3)- AR(2) was selected after returning with the lowest AIC (-6.4240) and highest log-likelihood (2297.93). The MS(3)-AR(2) was diagnosed for goodness of fit. The Q-statistics (independency) and Durbin Watson (DW; autocorrelation) test of residuals in each particular case were considered, the results of which are presented in Table 5 .

Table 4: MS-AR Estimation

\begin{tabular}{lllll}
\hline MS-AR Model & States & Lags & Log likelihood & AIC value \\
\hline MS(2)-AR(1) & 2 & 1 & 2291.867 & -6.4148 \\
MS(2)-AR(2) & 2 & 2 & 2287.950 & -6.4100 \\
MS(2)-AR(3) & 2 & 3 & 2283.808 & -6.4045 \\
MS(2)-AR(4) & 2 & 4 & 2280.228 & -6.4006 \\
MS(3)-AR(2) & 3 & 2 & 2297.930 & -6.4240 \\
MS(3)-AR(4) & 3 & 4 & 2288.735 & -6.4105 \\
\hline
\end{tabular}

Source: Researchers' computations using EViews

From the diagnosis of the goodness of fit of the models for the return series data presented in Table 5, the Q-statistics (p-value 0.161) and DW statistics (2.0266) show that there is no statistically significant trace of dependency and autocorrelation left in the squared standardized 
residual, indicating that the volatility model that is, $\operatorname{MS}(3)-\mathrm{AR}(2)$ is adequately specified. Table 5 displays the results of MS(3)-AR(2) and the coefficients for the regimes specifically the invariant error distribution coefficients. We see that all the regime-specific coefficients and variances $\left(\sigma_{\text {Regime } 1}^{2}=0.0208, \sigma_{\text {Regime } 2}^{2}=0.0034\right.$ and $\left.\sigma_{\text {Regime } 3}^{2}=0.0085\right)$ of the $\operatorname{MS}(3)-\operatorname{AR}(2)$ models are found to be significant at conventional level (5\%). Table 5 also shows the results of the transition probabilities, log-likelihood and AIC of the models. As a substitute to the transition matrix parameters of the MS(3)-AR(2) model, we examine the transition probabilities of the MS(3)-AR (2).

Furthermore, the transition probabilities for MS(3)-AR(2) model show that there is a high probability that the returns' system remains in the same state or regime hence implying limited switches in the state or regime. The results also indicate that the MS(3)-AR(2) has an $88 \%$ probability of staying in the accumulation/distribution regime and a $0.0018 \%$ and $12 \%$ probability of switching to the big-move and excess/panic regime respectively.

When the system is in a big-move regime, it has a $62 \%$ probability of remaining in the big-move regime and lower probabilities of $8.0 \mathrm{E}-06 \%$ and $38 \%$ to switch to accumulation/distribution and excess/panic regime respectively. Also, when the system is in excess/panic regime, it has a $78 \%$ probability of remaining in that regime and lower probabilities of $4.5 \%$ and $17 \%$ of switching to the accumulation/distribution regime and depreciation regime respectively. The transition probability results highlighted shows that only extreme/great events can switch the series between regimes i.e. regime 1(accumulation/distribution phase) to regime 2 (big-move phase) to regime 3 (excess/panic phase), (see Figure 3). It further indicates that not one regime is lasting since all transition probabilities are below one.

Based on expected duration results in Table 5, the accumulation/distribution regimes have average duration of 9 weeks while big-move and excess/panic regimes have 3 weeks and 4 weeks durations respectively for Nigeria All Share Index returns. Figure 3 displays the predicted regime probabilities for MS(3)-AR(2)-model. 


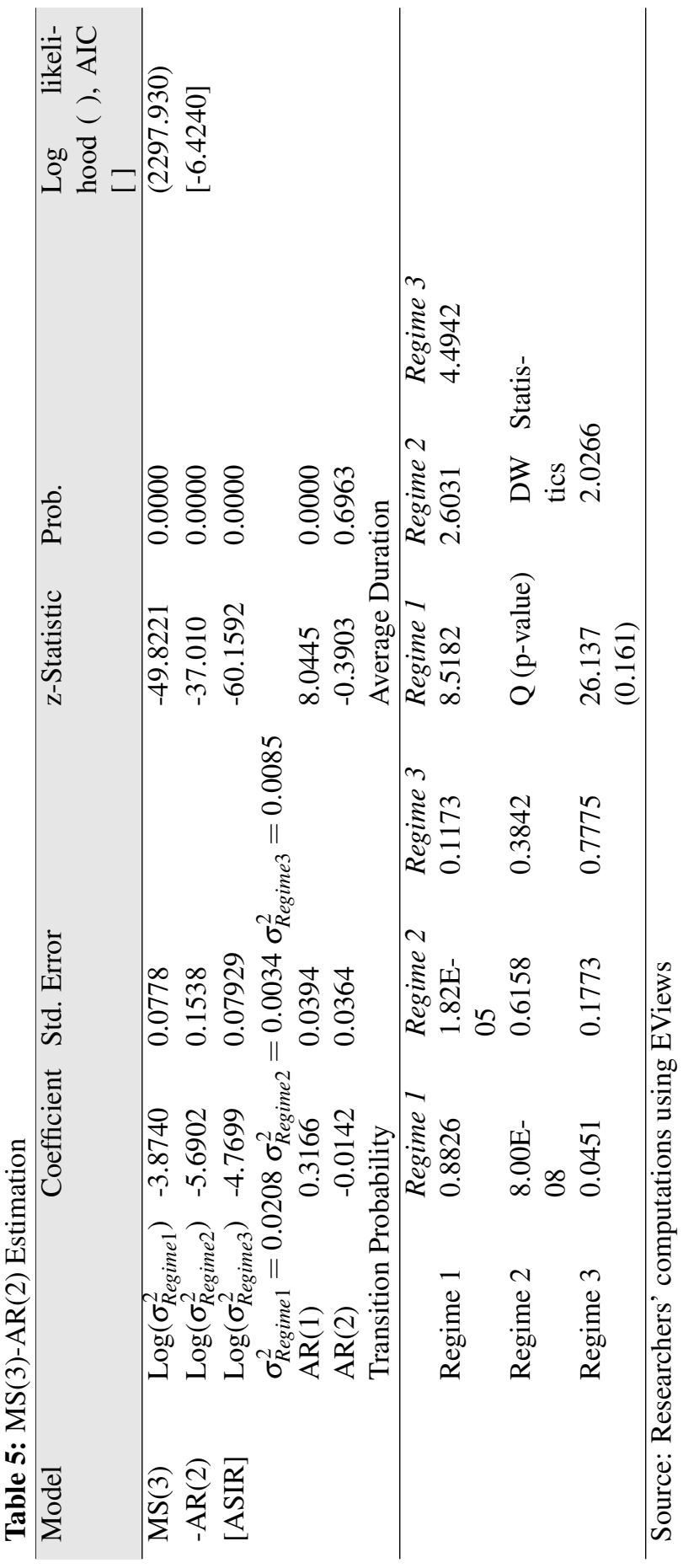




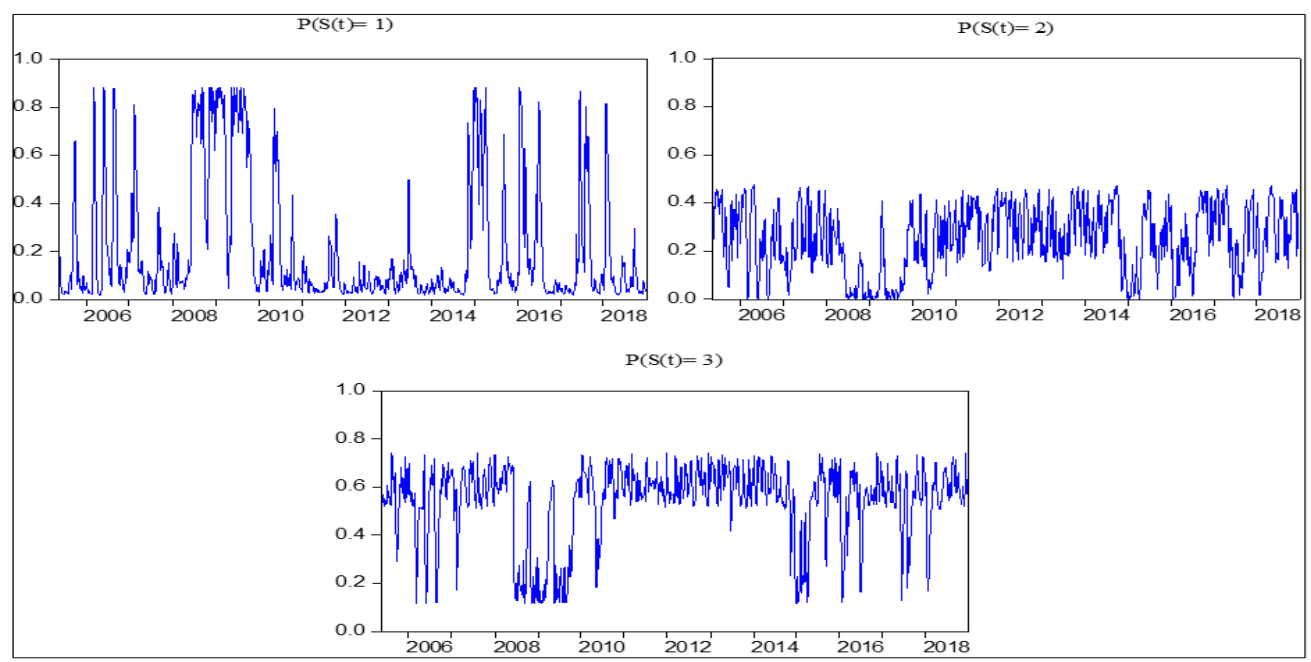

Figure 3: One-step Ahead Predicted Regime Probabilities returns.

\subsection{Forecast Evaluation}

The Markov-switching model i.e. MS(3)-AR(2) was estimated based on the weekly data from April 2005 to December 2018, and ex post forecasts are generated for the time period of January 2019 - September 2019. The plot of the MS(3)-AR(2) forecasts are depicted in Figure 4. To determine the performance of the fitted model in forecasting future ASIR pattern, Root Mean Square Error (RMSE), Mean Absolute Error (MAE), Mean Absolute Percentage Error (MAPE) and Theil's U criteria of the forecast sample ASI are estimated. The forecast analysis shows MS(3)-AR(2) as low as 0.002 (RMSE) and 0.0003 (MAE) (see Table 6). These two criteria incontrovertibly identify the fitted model as a good model capable to forecast the future of Nigeria All Share returns.

Table 6: Forecast Evaluation

\begin{tabular}{lc}
\hline RMSE & 0.001889 \\
MAE & 0.000299 \\
MAPE & 5.919255 \\
Theil-U & 0.0767247 \\
\hline \multicolumn{2}{l}{ Source: } \\
tions using EViews
\end{tabular}




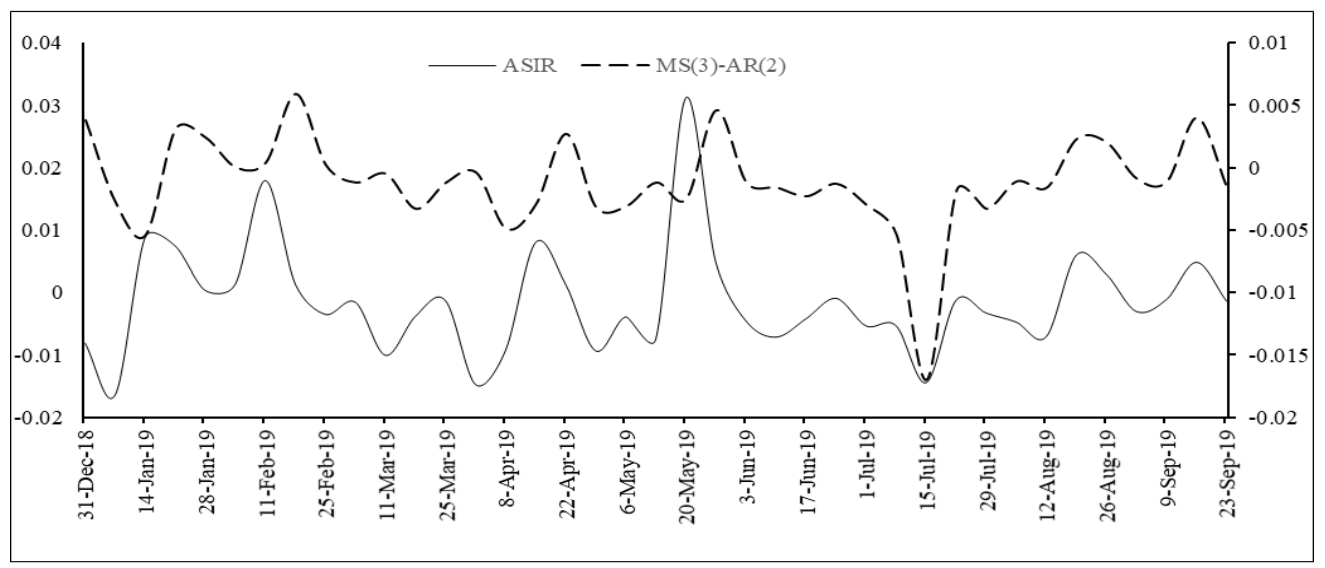

Figure 4: Estimated Models' Forecast

\section{Conclusion and Policy Recommendations}

This paper fits a suitable Markov Switching Autoregressive model to estimate the switching probabilities of Nigeria's stock market being in accumulation/distribution regime, big-move regime and excess/panic regime and forecast the Nigeria stock market returns. Prior to the MS-AR estimation, the descriptive statistics was presented and time series plots of the data i.e. All Share index (ASI) and its returns series (ASIR), heteroscedasticity test was also carried out to check that the return series meets the pre-condition (ARCH effect) for volatility model and lastly, the BDS test was conducted to identify the nonlinear feature of ASIR series.

Six MS-AR candidate models were estimated for the ASIR series. Based on least AIC value, MS(3)-AR(2) was returned as the most parsimonious model with the best goodness of fit among the six candidate models. The goodness of fit of the model for the return series [Qstatistics (p-value 0.161) and DW statistics (2.0266)] show that the most parsimonious model MS(3)-AR(2) was adequately specified. The MS(3)-AR(2) provides the empirical results of Nigeria's stock returns in three distinct phases; accumulation/distribution, big-move and excess/panic regimes. This finding is unique as compared to related studies such as Aliyu and Wambai (2018), Korkpoe and Howard (2019) and Yahaya and Adeoye (2020) whose studies provided evidence of Nigeria's stock market in two eras (appreciation and depreciation). Also, evidence from the three-regimes $[\operatorname{MS}(3)-\operatorname{AR}(2)]$ estimation, established a high probability that the returns' system remains in the same state, it implied that only unconventional or severe events can switch the series from regime 1(accumulation/distribution phase) 
to regime 2 (big-move phase) to regime 3 (excess/panic phase) and vice versa. Further, an average duration period of 9 weeks, 3 weeks and 4 weeks for the accumulation/distribution, big-move and excess/panic regimes respectively, were indicated. However, the transition probability and expected duration of the accumulation/distribution phase was higher compared to the big-move and excess/panic phases. This finding is similar to Aliyu and Wambai (2018) where higher transition probabilities were established in the appreciation phase compared to the depreciation era. Hence, it is evident that the MS-AR model is incontrovertibly robust and a valuable addition to the toolbox of modelling the stock market volatility in accumulation/distribution, big-move and excess/panic phases. Though not considered in this present study, in practical applications, for a more precise forecast, future studies could also consider the comparison of the performance of MS-AR model and GARCH-class of models.

Nevertheless, the policy recommendations of the aforementioned findings provide that the accumulation/distribution, big-move and excess/panic regimes' identification and their average durations are evident that the Nigeria's stock market is favorable for investors to trade. Also, the regime's identification and its average duration would guide the stakeholders and risk managers, who are interested in the state of Nigeria's stock market, in making investment policy that will enable them to trade in the market. Furthermore, for promising returns and following the expected durations of accumulation/distribution and big-more phases the investors could cautiously invest extra of their portfolio in stock during these regimes (particularly the big-move) as the market verges to experience the height of trades with high probabilities to switch to panic phase.

\section{References}

Adam, H., (2020). Dow theory. Investopedia. https://www.investopedia.com/terms/d/dowtheory.asp

Adeolu, B. (2012). Restoring investor confidence and value creation in the Nigerian capital market. The Nigerian Stock Exchange.

Aikaterini, N. (2016). The predictive power of regime switching models for stock market. Interdepartmental programme of postgraduate studies in economics (Master in Economics), Thesis, University of Macedonia.

Aliyu, S. U. R. \& Wambai, A. A. (2018). Economic regimes and stock market performance in Nigeria: Evidence from regime switching model. Munich Personal RePEc Archive MPRA, 91430. Retrieve from https://mpra.ub.uni-muenchen.de/91430/ 
Andersen, T. \& Bollerslev, T. (1998). Answering the sceptics: Yes, standard volatility models do provide accurate forecasts. International Economic Review, 39, 885-905.

Bala, D. A. \& Asemota, O. J. (2013). Exchange rates volatility in Nigeria; Application of GARCH models with exogenous break. CBN Journal of Applied Statistics, 4(1).

Barndorff-Nelsen, O. E. \& Shephard, N. (2002). Econometric analysis of realized volatility and its use in estimating stochastic volatility models. Journal of the Royal Statistics Society, 64(2), 253-280.

Beckmann, J. \& Czudaj, R. (2013). The forward pricing function of industrial metal futures - Evidence from cointegration and smooth transition regression analysis. International Review of Applied Economics, 27, 472-490.

Box, G. E. P. \& Jenkins, G. M. (1976). Time series analysis and control, 2nd edition, Holden Day, San Francisco.

Brooks, C. \& Burke, S.P. (1998). Forecasting exchange rate volatility using conditional variance models selected by information criteria. Economics Letters, 61, 273-278.

Calvet, L. \& Fisher, A. (2004). Regime-switching and the estimation of multifractal processes. Journal of Financial Econometrics, 2, 44-83.

Goldfeld, S. M. \& Quandt, R.E. (1976). Studies in nonlinear estimation. Cambridge, MA: Ballinger Publishing Company.

Hamilton, J. D. (1989). A new approach to the economic analysis of nonstationary time series and the business cycle. Econometrica, 57(2), 357-384.

Hamilton, J. D. (1990). Analysis of time series subject to changes in regime. Journal of econometrics, 45, 39-70.

Hsieh, D. (1989). Testing for nonlinear dependence in daily foreign exchange rates. Journal of Business, 339-368.

Jorion, P. (1995). Predicting volatility in the foreign exchange market. The Journal of Finance, 50(2) 507-528.

Korkpoe C. H \& Howard N. (2019). Volatility model choice for sub-Saharan frontier equity markets - A Markov regime switching Bayesian approach. Emerging Markets Journal, 9(1), 172. Doi10.5195/emaj.2019.172

Lastrapes, W. D. (1989). Exchange rate volatility and U.S. monetary policy: An ARCH application. Journal of Money, Credit, and Banking, 21, 66-77.

Longmore, R. \& Robinson W. (2004). Modelling and forecasting exchange rate dynamics: An application of asymmetric volatility models. Bank of Jamaica. Working Paper WP2004/03 
Lux T., Morales-Arias L., \& Sattarho C. (2014). A Markov-switching multifractal approach to forecasting realized volatility. Journal of Forecasting, 33, 532-541.

Lux T., Segnon M. \& Gupta R. (2015). Modelling and forecasting crude oil price volatility; Evidence from historical data.

Maqsood A., Safdar S., Shafi, R. \& Lelit, N.J. (2017). Modeling stock market volatility using garch models: a case study of Nairobi securities exchange (NSE). Open Journal of Statistics, 7, 369-381.

Masoud Y., Hamidreza M., \& Safaei M. (2012). Markov switching models for time series data with dramatic jumps. Sains Malaysiana 41(3), 371-377.

McKenzie, M. D. (1997). ARCH modelling of Australian bilateral exchange rate data. Applied Financial Economics, 7, 147 - 164.

Meese, R. \& Rogoff, K. (1983). Empirical exchange rate models of the seventies: Do they fit the out of sample? Journal of International Economics, 14, 3-24.

Mendy, D. \& Widodo, T. (2018). "Two stage Markov switching model: Identifying the Indonesian Rupiah Per US Dollar turning points post 1997 financial crisis," MPRA Paper 86728.

Milhoj, A. (1987). A conditional variance model for daily observations of an exchange rate. Journal of Business and Economic Statistics, 5, 99-103.

Nguyen, D. K. \& Walid, C. (2014). Exchange rate movements and stock market returns in a regime-switching environment: Evidence for BRICS countries. IPAG Business School, Paris Working Paper. https://www.ipag.fr/fr/accueil/larecherche/publicationsWP.html

Pesaran, B. \& Robinson G. (1993). The European exchange rate mechanism and the volatility of the sterling-deutschmark exchange rate. Economic Journal, 103, 1418-1431.

Poon, S. H., \& Granger, C. W. J. (2003). Forecasting volatility in financial markets: A review. Journal of Economic Literature, XLI, 478-539.

Shamsudeen I. M., Galadanchi G. S., Mai-Unguwa H., Ayantunji B. G. \& Bawa M. (2015). Study of average hourly variation of radio refractivity variations across some selected cities in Nigeria. IQSR Journal of Applied Physics, 7(6), 27-43.

Taylor, S. J. (1987). Forecasting the volatility of currency exchange rates. International Journal of Forecasting, 3, $159-70$.

Tse, Y. K. \& Tsui, A. K. (1997). Conditional volatility in foreign exchange rates: Evidence from the Malaysian Ringgit and Singapore Dollar. Pacific Basin Finance Journal 5, 345-356. 
Tule M., Dogo M. \& Uzonwanne G. (2018). Volatility of stock market returns and the naira exchange rate. Global Finance Journal, 35, 97-105.

Wang, T. A. (2006). Does Implied volatility of futures currency option implied volatility of exchange rates? Elsevier, Physica, 374, 773-782.

Yahaya H. U. \& Adeoye M. (2020). A Markov regime switching approach of estimating volatility using Nigeria stock market. American Journal of Theoretical and Applied Statistics, 9(4), 80-89. DOI: 10.11648/j.ajtas.20200904.11

Yaya O. S., Akinlana, D. M. \& Shittu, O. I. (2016). Modeling Nigerian banks' share prices using smooth transition GARCH models. CBN Journal of Applied Statistics, 7(2), $137-158$.

Zhu, X. \& Zhu, J. (2013). Predicting stock returns: A regime-switching combination approach and economic links. Journal of Banking and Finance, 37(11), 4120-4233. 